\title{
Effect of bottom water on performance of cyclic superheated steam stimulation using a horizontal well
}

\author{
Fengrui Sun ${ }^{1,2,3} \cdot$ Yuedong Yao ${ }^{1,2,3} \cdot$ Guozhen $\mathrm{Li}^{3}$
}

Received: 7 December 2018 / Accepted: 7 February 2019 / Published online: 13 February 2019

(c) The Author(s) 2019

\begin{abstract}
Horizontal well has been widely used for heavy-oil recovery in the petroleum industry. Besides, superheated steam has been proved effective in heavy-oil recovery by field practice. In this paper, a numerical model is established with the help of numerical simulator. The effect of bottom water on the productivity of cyclic superheated steam stimulation well has been studied. Some interesting findings show that: (a) the bottom water-channeling phenomenon becomes more severe when the horizontal well is approaching the bottom water. (b) The cyclic oil production fluctuates with periodic number when the horizontal well is close to the bottom water due to the fact that the injected water has an elastic push action on the bottom water. (c) A larger-bottom water size is able to supply a larger elastic energy. While the cyclic oil production of large-bottom water size for the first few cycles is smaller than that with a small-bottom water, it may be turned over for the last few cycles.
\end{abstract}

Keywords Heavy oil $\cdot$ Horizontal well $\cdot$ Cyclic superheated steam stimulation $\cdot$ Bottom water $\cdot$ Size of water body . Numerical analysis

\section{Introduction}

Horizontal wells have been widely used for heavy-oil recovery, as well as geothermal energy development (Fengrui et al. 2017a, b, Fengrui et al. 2018a, b, c). In the heavy-oil industry, horizontal wells are always selected for the steamassisted gravity drainage process, steam flooding, as well as the cyclic steam stimulation process (Fengrui et al. 2018d, e, f, g, h, i, j, k, 1, 2019a; Ganesh et al. 2019; Zargar and Ali 2018; Baghernezhad et al. 2019; Venkatramani and Okuno 2018; Bao et al. 2016). This is because, compared with the

\section{Fengrui Sun \\ 13126682711@163.com \\ Yuedong Yao \\ 1181890005@qq.com \\ $\triangle$ Guozhen Li \\ 1174107928@qq.com}

1 State Key Laboratory of Petroleum Resources and Prospecting, China University of Petroleum, Beijing 102249, People's Republic of China

2 College of Petroleum Engineering, China University of Petroleum, Beijing 102249, People's Republic of China

3 China University of Petroleum, Beijing 102249, People's Republic of China vertical well, horizontal well processes the multi-advantages of a larger contact area with oil reservoir, a higher production rate as well as a larger well-controlled volume (Khan and Awotunde 2018; Muradov and Davies 2012).

On the other hand, the selection of thermal fluid is an important task in the thermal industry (Fengrui et al. 2017c, $\mathrm{d}, \mathrm{e}, \mathrm{f}, \mathrm{g}$ ). From the physical aspect of view, it is always focused on the mass and heat transfer characteristics of thermal fluid in the study system (Fengrui et al. 2018m, n, o).

In recent years, superheated steam (Fengrui et al. 2018p, q, r, 2019b), supercritical $\mathrm{CO}_{2}$ and multi-component thermal fluid (Haitang et al. 2019; Fengrui et al. 2017h, 2018s, $\mathrm{t}, \mathrm{u}, \mathrm{v}, 2019 \mathrm{c}, \mathrm{h}$ ) were widely adopted in thermal recovery of heavy oil as well as in geothermal energy recovery (Fengrui et al. 2018w, x, 2019c, d, e, f, g). In this paper, superheated steam is selected as the study object. A model of cyclic superheated steam stimulation in a bottom-water heavy-oil reservoir is established with the numerical simulator. Then, the effect of bottom water on the performance of cyclic superheated steam stimulation well has been studied. 
Table 1 Reservoir and operation parameters of the numerical model

\begin{tabular}{llll}
\hline Physical parameter & Value & Physical parameter & Value \\
\hline Reservoir size $(\mathrm{m})$ & $450 \times 200 \times 20$ & Superheated steam temperature $\left({ }^{\circ} \mathrm{C}\right)$ & 316 \\
Grid size $(\mathrm{m})$ & $10 \times 10 \times 2$ & Soak time (day) & 10 \\
Buried depth (m) & 300 & Injection pressure $(\mathrm{kPa})$ & 5000 \\
Porosity, dimensionless & 35.6 & Length of the horizontal well $(\mathrm{m})$ & 250 \\
Rock compression coefficient $^{\left(\mathrm{kPa}^{-1}\right)}$ & $3.65 \times 10^{-5}$ & Reservoir temperature $\left({ }^{\circ} \mathrm{C}\right)$ & 13.5 \\
\hline
\end{tabular}

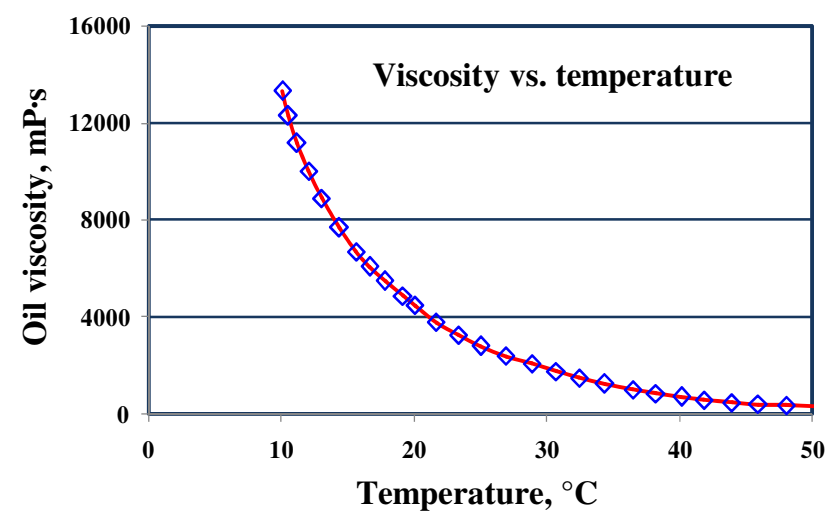

Fig. 1 Oil viscosity vs. temperature

\section{The numerical model}

With the help of numerical simulator, a model is built for the cyclic superheated steam stimulation well with a bottom water body. The reservoir thickness is $20 \mathrm{~m}$. The permeability in the I direction is $1000 \mathrm{mD}$. The distance of horizontal well to bottom water is $12 \mathrm{~m}$. The oil saturation is 0.79 . The viscosity of oil under reservoir condition is $8500 \mathrm{mPa}$ s. The ratio of vertical permeability to horizontal permeability is 0.3 . The superheated degree is $30 \mathrm{~K}$. The periodic steam injection is $2000 \mathrm{t}$. The other parameters are shown in Table 1.

The viscosity of heavy oil against temperature is shown in Fig. 1. It is observed that the viscosity of heavy oil is close to zero when the temperature is higher than $50{ }^{\circ} \mathrm{C}$.

The relative permeability curve adopted in this paper is shown in Fig. 2. Figure 2a shows the oil and water relative permeability, while Fig. $2 b$ shows the gas and liquid relative permeability.

The $3 \mathrm{D}$ view and the $\mathrm{I}-\mathrm{J}$ view of the numerical model is shown in Fig. 3. The half above is the oil reservoir, while the below half is the bottom water. Note that the capillary force is neglected in this paper so that there is a clear boundary between oil and bottom water.
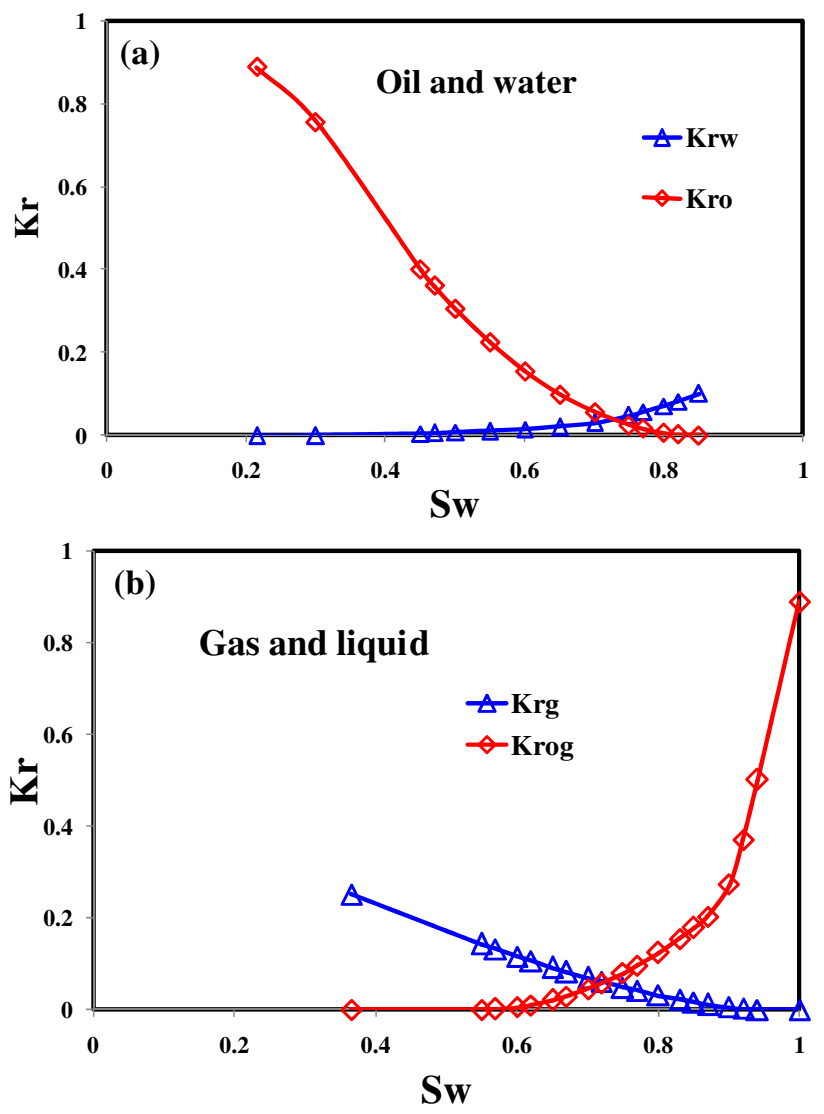

Fig. 2 The relative permeability adopted in the numerical simulation

\section{Results and discussion}

In oil field, one of the key issues is to determine the distance from horizontal well to bottom water. In this part, the effect of distance from horizontal well to bottom water on performance of cyclic superheated steam stimulation wells has been revealed. The distances are selected as $4 \mathrm{~m} .8 \mathrm{~m}, 12 \mathrm{~m}$, 16 m. The simulated results are shown in Figs. 4 and 5.

Figure 4 shows the macroscopic law of the effect of distance from horizontal well to bottom water on final recovery degree. It is observed that the final recovery degree increases with increase of the distance. This is because the bottom water-channeling phenomenon becomes more severe when 

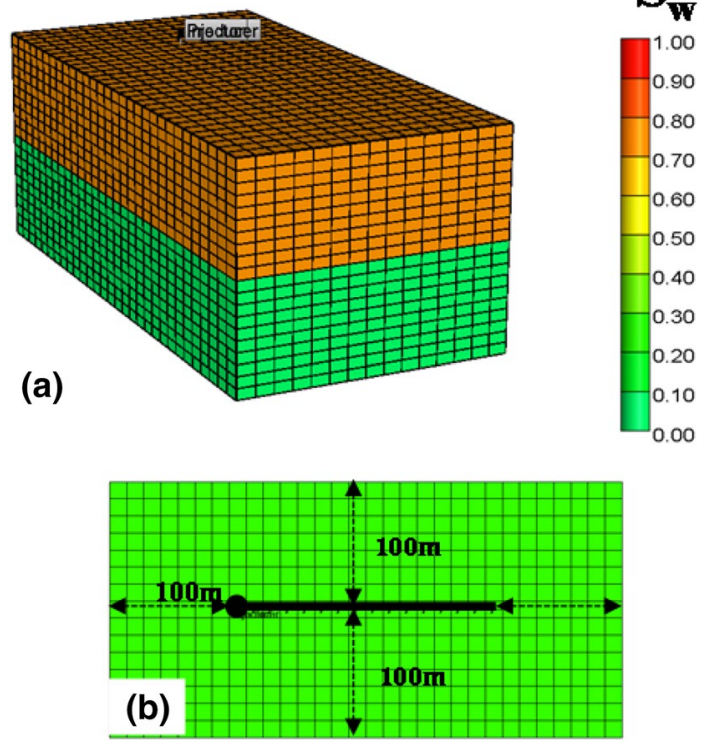

Fig. 3 The sketch map for the numerical model

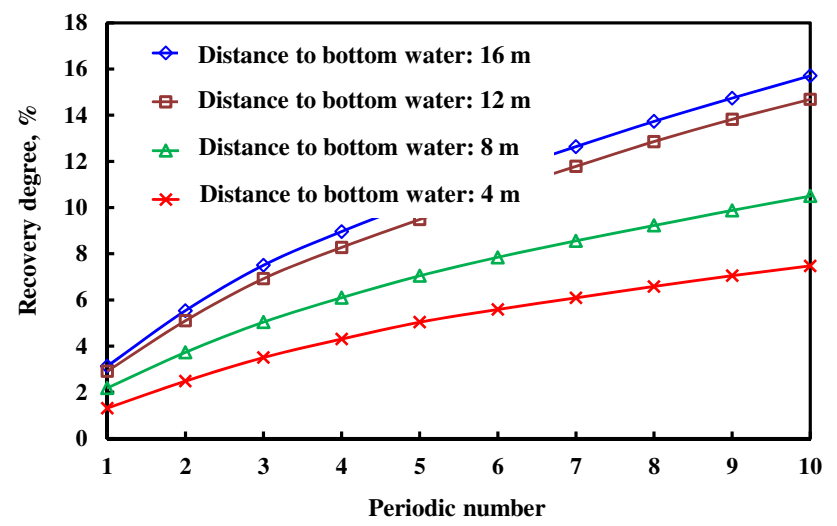

Fig. 4 Effect of distance from horizontal well to bottom water on final recovery degree

the horizontal well is approaching the bottom water. The curves shown in Fig, 4 are the accumulative values of the cyclic oil production rate. A further view is shown in Fig. 5 to reveal the cyclic performance.

Figure 5 shows the effect of distance from horizontal well to bottom water on cyclic oil production. It is observed that: (a) the cyclic oil production decreases with periodic number. This is because the oil saturation and reservoir pressure decrease with periodic number. (b) Another interesting phenomenon is that the cyclic oil production fluctuates with periodic number when the horizontal well is close to the bottom water. For instance, the cyclic oil production for the sixth cycle is smaller than both the fifth cycle and the seventh cycle. This is because

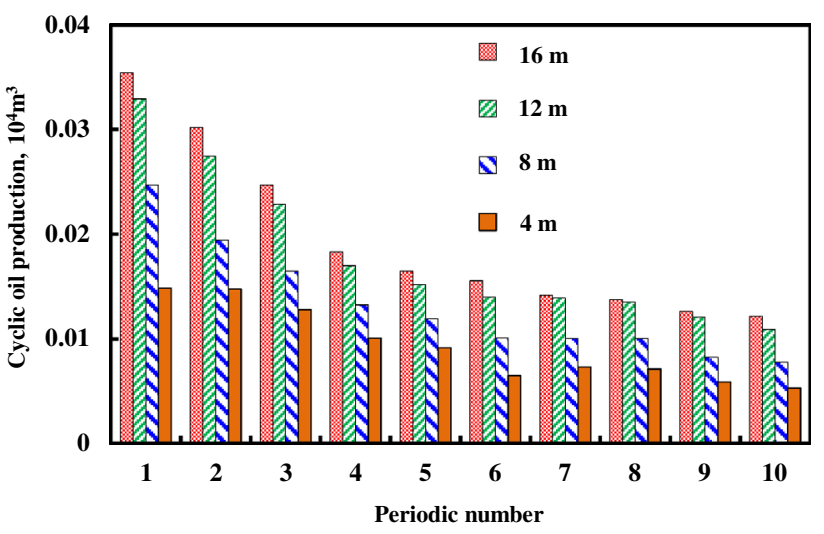

Fig. 5 Effect of distance from horizontal well to bottom water on cyclic oil production

the injected water has an elastic push action on the bottom water, which is shown in Fig. 6.

Figure 6 shows the water saturation at heel-point of the horizontal well at the end of soak period of the sixth and seventh cycle. It is observed that the bottom water has been pushed back to a lower position after the superheated steam has been injected into the reservoir in the seventh cycle. Consequently, the water saturation near the heel-point of wellbore has been decreased. This is the main reason why the productivity of the following cycle may be higher than its previous cycle, as shown in Fig. 5.

However, the cyclic oil production rate always decreases with periodic number when the horizontal well is far from the bottom water. It is observed from Fig. 7 that: (a) the bottom water reaches the wellbore at the end of the first cycle. The water saturation near the wellbore increases with periodic number. (b) The bottom water is hard to reach when the wellbore distance is equal to $12 \mathrm{~m}$. As a result, the thermal well should be located at the upper part of the reservoir to prevent the bottom water-coning phenomenon from happening too early.

Another issue is studied to reveal the effect of bottom water body size on the oil productivity rate. The simulated results are shown in Figure 8 where the effect of bottom water body size on the recovery degree can be seen. It is observed that the recovery degree has been greatly decreased when there is a bottom water body. What's more, the recovery degree decreases with bottom water size. However, a larger bottom water size is able to supply a larger elastic energy, as shown in Fig. 9. It is observed from Fig. 9 that the cyclic oil production decreases with periodic number when the bottom water size is at a small level. However, when the bottom water size is 20 times of reservoir, the cyclic oil production decreases slowly with periodic number. Besides, while the cyclic oil production of large bottom water size for the first few cycles is smaller than that with

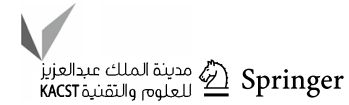


Fig. 6 Interpretation for the fluctuation phenomenon of cyclic oil production when the horizontal well is close to the bottom
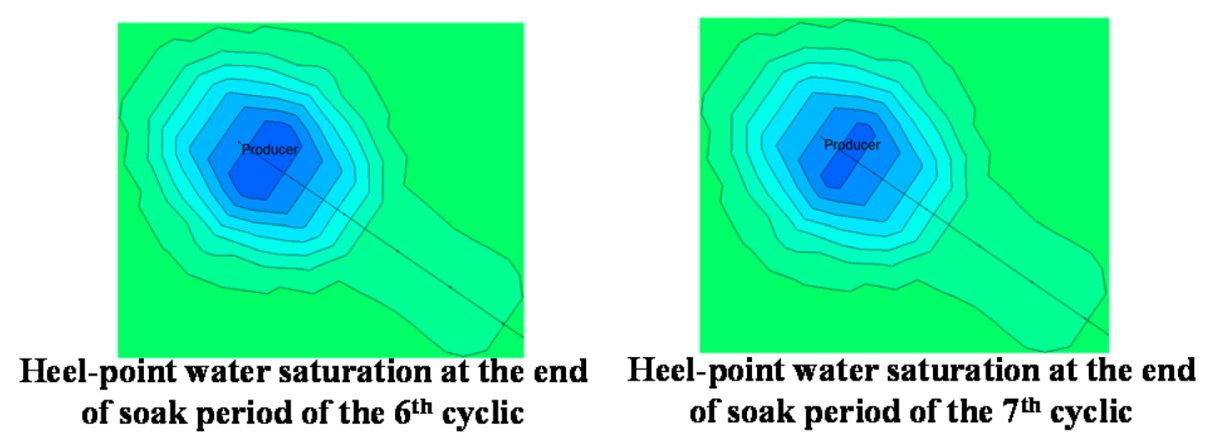

of soak period of the $7^{\text {th }}$ cyclic
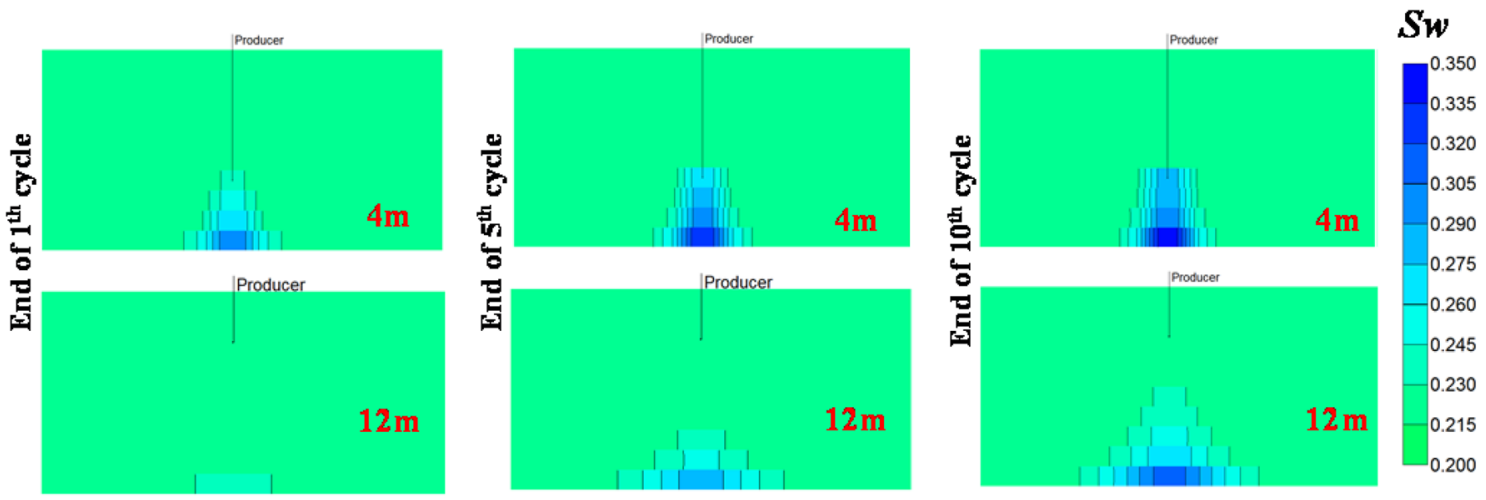

Fig. 7 Bottom water-coning phenomenon under different distance from horizontal well to bottom water condition

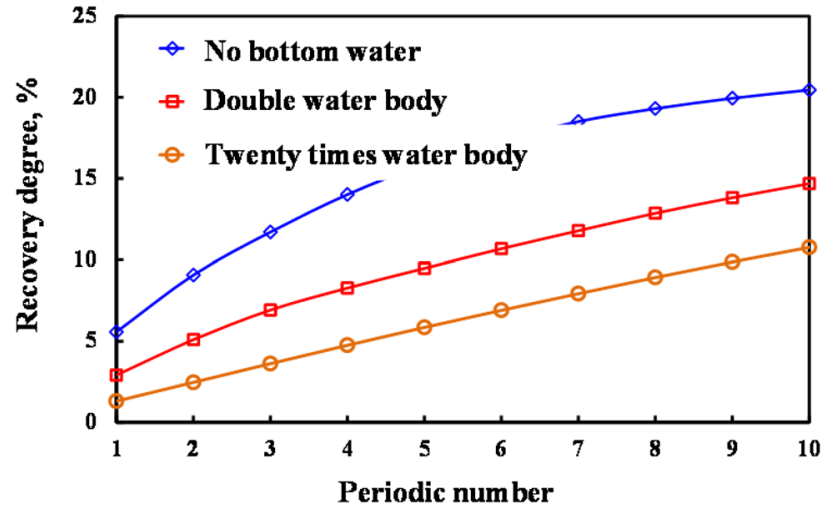

Fig. 8 Effect of bottom water body size on the recovery degree

a small bottom water, it may be turned over for the last few cycles. This is because the large bottom water possesses a larger elastic energy which can be used for oil production when the reservoir pressure has been greatly decreased for the last few cycles.

For further learning on superheated steam injection for heavy-oil recovery, the following articles are recommended (Xu et al. 2013; Chen et al. 2018; Kondoh et al. 2016; Ajumobi et al. 2018; Fan et al. 2016; Liu et al. 2018).

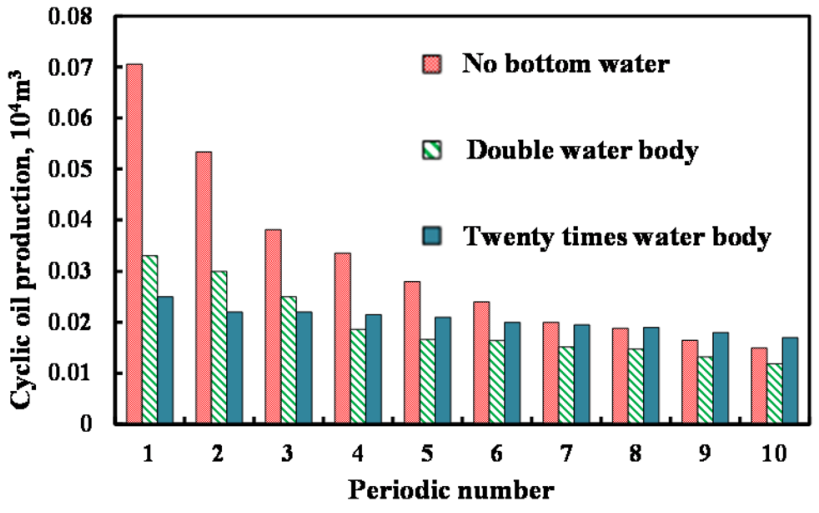

Fig. 9 Effect of bottom water body size on the cyclic oil production

\section{Conclusion}

In this paper, a numerical model is established with the help of numerical simulator. The effect of bottom water on the productivity of cyclic superheated steam stimulation well has been studied. Some interesting findings are shown below.

(a) The bottom water-channeling phenomenon becomes more severe when the horizontal well is approaching the bottom water. 
(b) The cyclic oil production fluctuates with periodic number when the horizontal well is close to the bottom water due to the fact that the injected water has an elastic push action on the bottom water.

(c) A larger bottom water size is able to supply a larger elastic energy. While the cyclic oil production of large bottom water size for the first few cycles is smaller than that with a small bottom water, it may be turned over for the last few cycles.

\begin{abstract}
Acknowledgements The research was supported by National Science and Technology Major Projects of China (no. 2016ZX05042, no. 2017ZX05039 and 2016ZX05039) and the National Natural Science Foundation Projects of China (no. 51504269, no. 51490654 and no. 40974055). The authors also acknowledge Science Foundation of China University of Petroleum, Beijing (no. C201605), the National Basic Research Program of China (2015CB250900), the Program for New Century Excellent Talents in University (Grant no. NCET-131030) to support part of this work.
\end{abstract}

Open Access This article is distributed under the terms of the Creative Commons Attribution 4.0 International License (http://creativeco mmons.org/licenses/by/4.0/), which permits unrestricted use, distribution, and reproduction in any medium, provided you give appropriate credit to the original author(s) and the source, provide a link to the Creative Commons license, and indicate if changes were made.

\section{References}

Ajumobi OO, Muraza O, Kondoh H (2018) Upgrading oil sand bitumen under superheated steam over ceria-based nanocomposite catalysts. Appl Energy 218(15):1-9

Baghernezhad D, Siavashi M, Nakhaee A (2019) Optimal scenario design of steam-assisted gravity drainage to enhance oil recovery with temperature and rate control. Energy 166(1):610-623

Bao Y, Wang J, Gates ID (2016) On the physics of cyclic steam stimulation. Energy 115(1):969-985

Chen Z, Zhou J, Chen Z et al (2018) A laboratory evaluation of superheated steam extraction process for decontamination of oil-based drill cuttings. J Environ Chem Eng 6(5):6691-6699

Fan Z, He C, Xu A (2016) Calculation model for on-way parameters of horizontal wellbore in the superheated steam injection. Pet Explor Dev 43(5):798-805

Fengrui S, Yuedong Y, Xiangfang L, Lin Z (2017a) Type curve analysis of superheated steam flow in offshore horizontal wells. Int J Heat Mass Transf 113:850-860

Fengrui S, Yuedong Y, Xiangfang L, Lin Z, Guanyang D, Xuejiao Z (2017b) The mass and heat transfer characteristics of superheated steam coupled with non-condensing gases in perforated horizontal wellbores. J Pet Sci Eng 156:460-467

Fengrui S, Yuedong Y, Xiangfang L, Pengliang Y, Guanyang D, Ming $Z(2017 c)$ The flow and heat transfer characteristics of superheated steam in offshore wells and analysis of superheated steam performance. Comput Chem Eng 100:80-93

Fengrui S, Yuedong Y, Mingqiang C, Xiangfang L, Lin Z, Ye M, Zheng S, Tao Z, Dong F (2017d) Performance analysis of superheated steam injection for heavy oil recovery and modeling of wellbore heat efficiency. Energy 125:795-804

Fengrui S, Yuedong Y, Xiangfang L, Pengliang Y, Lin Z, Yi Z (2017e) A numerical approach for obtaining type curves of superheated multi-component thermal fluid flow in concentric dual-tubing wells. Int J Heat Mass Transf 111:41-53

Fengrui S, Yuedong Y, Xiangfang L, Ji T, Guojin Z, Zhiming C (2017f) The flow and heat transfer characteristics of superheated steam in concentric dual-tubing wells. Int J Heat Mass Transf 115:1099-1108

Fengrui S, Yuedong Y, Xiangfang L, He L, Gang C, Zheng S (2017g) A numerical study on the non-isothermal flow characteristics of superheated steam in ground pipelines and vertical wellbores. J Pet Sci Eng 159:68-75

Fengrui S, Yuedong Y, Xiangfang L (2017h) Effect of gaseous $\mathrm{CO}_{2}$ on superheated steam flow in wells. Eng Sci Technol Int J 20(6):1579-1585

Fengrui S, Yuedong Y, Xiangfang L (2018a) The heat and mass transfer characteristics of superheated steam coupled with non-condensing gases in horizontal wells with multi-point injection technique. Energy 143:995-1005

Fengrui S, Yuedong Y, Xiangfang L, Guozhen L, Yanan M, Song H, Zhili C (2018b) Flow simulation of the mixture system of supercritical $\mathrm{CO}_{2}$ and superheated steam in toe-point injection horizontal wellbores. J Pet Sci Eng 163:199-210

Fengrui S, Yuedong Y, Xiangfang L, Guozhen L, Zheng S (2018c) A numerical model for predicting distributions of pressure and temperature of superheated steam in multi-point injection horizontal wells. Int J Heat Mass Transf 121:282-289

Fengrui S, Yuedong Y, Xiangfang L, Guozhen L, Qing L, Song H, Yunjian Z (2018d) Effect of friction work on key parameters of steam at different state in toe-point injection horizontal wellbores. J Pet Sci Eng 164:655-662

Fengrui S, Yuedong Y, Xiangfang L, Guozhen L, Song H, Qing L, Wenyuan L (2018e) Type curve analysis of multi-phase flow of multi-component thermal fluid in toe-point injection horizontal wells considering phase change. J Pet Sci Eng 165:557-566

Fengrui S, Yuedong Y, Guozhen L, Xiangfang L, Tao Z, Chengang L, Wenyuan L (2018f) An improved two-phase model for saturated steam flow in multi-point injection horizontal wells under steady-state injection condition. J Pet Sci Eng 167:844-856

Fengrui S, Yuedong Y, Guozhen L, Xiangfang L (2018g) Geothermal energy extraction in $\mathrm{CO}_{2}$ rich basin using abandoned horizontal wells. Energy 158:760-773

Fengrui S, Yuedong Y, Guozhen L, Xiangfang L, Qian L, Jian Y, Jiqiang W (2018h) A coupled model for $\mathrm{CO}_{2}$ and superheated steam flow in full-length concentric dual-tube horizontal wells to predict the thermophysical properties of $\mathrm{CO}_{2}$ and superheated steam mixture considering condensation. J Pet Sci Eng 170:151-165

Fengrui S, Yuedong Y, Guozhen L, Xiangfang L (2018i) Performance of geothermal energy extraction in a horizontal well by using $\mathrm{CO}_{2}$ as the working fluid. Energy Convers Manag 171:1529-1539

Fengrui S, Yuedong Y, Guozhen L (2018j) Comments on heat and mass transfer characteristics of steam in a horizontal wellbore with multi-point injection technique considering wellbore stock liquid. Int J Heat Mass Transf 127:949-958

Fengrui S, Yuedong Y, Xiangfang L (2018k) The heat and mass transfer characteristics of superheated steam in horizontal wells with toe-point injection technique. J Pet Explor Prod Technol 8(4):1295-1302

Fengrui S, Yuedong Y, Guozhen L, Shiyuan Q, Shikun Z, Yu S, Zhengming X, Xiangfang L (20181) Effect of pressure and temperature of steam in parallel vertical injection wells on productivity of a horizontal well during the SAGD process: a numerical case study. In: SPE international heavy oil conference and exhibition, SPE-193659-MS, 10-12 December 2018 in Kuwait City, Kuwait

Fengrui S, Yuedong Y, Xiangfang L, Guozhen L, Zhili C, Yucui C, Meng C, Song H, Lv C, Dong F, Zheng S (2018m) Effect of

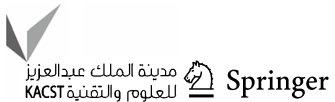


flowing seawater on supercritical $\mathrm{CO}_{2}$ - superheated water mixture flow in an offshore oil well considering the distribution of heat generated by the work of friction. J Pet Sci Eng 162:460-468

Fengrui S, Yuedong Y, Xiangfang L, Guozhen L, Liang H, Hao L, Zhili C, Qing L, Wenyuan L, Meng C, Song H (2018n) Exploitation of heavy oil by supercritical $\mathrm{CO}_{2}$ : effect analysis of supercritical $\mathrm{CO}_{2}$ on $\mathrm{H}_{2} \mathrm{O}$ at superheated state in integral joint tubing and annuli. Greenh Gases Sci Technol 8(3):557-569

Fengrui S, Yuedong Y, Guozhen L, Xiangfang L, Mingqiang C, Gang C, Tao Z (2018o) Analysis of superheated steam performance in offshore concentric dual-tubing wells. J Pet Sci Eng 166:984-999

Fengrui S, Yuedong Y, Guozhen L, Xiangfang L (2018p) Numerical simulation of supercritical-water flow in concentric-dual-tubing wells. SPE J 23(6):2188-2201

Fengrui S, Yuedong Y, Guozhen L, Xiangfang L, Chengang L, Zhili C (2018q) A model for predicting thermophysical properties of water at supercritical state in offshore CDTW. Measurement 124:241-251

Fengrui S, Yuedong Y, Guozhen L, Xiangfang L (2018r) Geothermal energy development by circulating $\mathrm{CO}_{2}$ in a U-shaped closed loop geothermal system. Energy Convers Manag 174:971-982

Fengrui S, Yuedong Y, Guozhen L (2018s) Comments on: the flow and heat transfer characteristics of compressed air in high-pressure air injection wells. Arab J Geosci 11(20):631

Fengrui S, Yuedong Y, Xiangfang L (2018t) Numerical simulation of superheated steam flow in dual-tubing wells. J Pet Explor Prod Technol 8(3):925-937

Fengrui S, Yuedong Y, Xiangfang L (2018u) Effect analysis of noncondensable gases on superheated steam flow in vertical singletubing steam injection pipes based on the real gas equation of state and the transient heat transfer model in formation. J Pet Explor Prod Technol 8(4):1325-1330

Fengrui S, Yuedong Y, Xiangfang L, Guozhen L (2018v) A brief communication on the effect of seawater on water flow in offshore wells at supercritical state. J Pet Explor Prod Technol 8(4): 1587-1596

Fengrui S, Yuedong Y, Guozhen L, Lin Z, Hao L, Xiangfang L (2018w) Water performance in toe-point injection wellbores at supercritical state. In: SPE trinidad and tobago section energy resources conference, SPE-191151-MS, 25-26 June 2018 in Port of Spain, Trinidad and Tobago. https://doi.org/10.2118/191151-MS

Fengrui S, Yuedong Y, Guozhen L, Xiangfang L, Jian S (2018x) Comparison of steam front shape during steam flooding process under varying steam state condition: numerical analysis. In: Abu Dhabi international petroleum exhibition and conference, SPE192996-MS, 12-15 November, 2018, Abu Dhabi, UAE. https:// doi.org/10.2118/192996-MS

Fengrui S, Yuedong Y, Guozhen L (2019a) Comments on heat and mass transfer characteristics of steam in a horizontal wellbore with multi-point injection technique considering wellbore stock liquid. Int J Heat Mass Transf 132:1319-1321

Fengrui S, Yuedong Y, Guozhen L, Shikun Z, Zhengming X, Yu S, Xiangfang L (2019b) A slip-flow model for oil transport in organic nanopores. J Pet Sci Eng 172:139-148

Fengrui S, Yuedong Y, Xiangfang L, Guozhen L (2019c) An analytical equation for oil transport in nanopores of oil shale considering viscosity distribution. J Pet Explor Prod Technol. https://doi. org/10.1007/s13202-018-0486-8

Fengrui S, Yuedong Y, Guozhen L (2019d) New analytical equations for productivity estimation of the cyclic $\mathrm{CO}_{2}$-assisted steam stimulation process considering the non-Newtonian percolation characteristics. J Pet Explor Prod Technol. https://doi.org/10.1007/ s13202-018-0518-4

Fengrui S, Yuedong Y, Guozhen L, Xiangfang L (2019e) Effect of physical heating on productivity of cyclic superheated steam stimulation wells. J Pet Explor Prod Technol. https://doi.org/10.1007/ s13202-018-0527-3

Fengrui S, Yuedong Y, Guozhen L, Xiangfang L (2019f) Effect of critical thickness on nanoconfined water fluidity: review, communication, and inspiration. J Pet Explor Prod Technol. https:// doi.org/10.1007/s13202-018-0540-6

Fengrui S, Yuedong Y, Guozhen L (2019g) Slight insights and perspectives of future heavy oil recovery. J Pet Explor Prod Technol. https ://doi.org/10.1007/s13202-019-0615-Z

Fengrui S, Yuedong Y, Guozhen L, Wenyuan L (2019h) A numerical model for wet steam circulating in horizontal wellbores during starting stage of the steam-assisted-gravity-drainage process. Heat Mass Transf. https://doi.org/10.1007/s00231-019-02564-7

Ganesh A, Xiong J, Chalaturnyk RJ, Prasad V (2019) Proxy models for caprock pressure and temperature dynamics during steam-assisted gravity drainage process. Comput Chem Eng 121(2):594-607

Haitang Y, Qi L, Fengrui S (2019) Numerical simulation of $\mathrm{CO}_{2}$ circulating in a retrofitted geothermal well. J Pet Sci Eng 172:217-227

Khan RA, Awotunde AA (2018) Determination of vertical/horizontal well type from generalized field development optimization. J Pet Sci Eng 162:652-665

Kondoh H, Tanaka K, Nakasaka Y, Tago T, Masuda T (2016) Catalytic cracking of heavy oil over $\mathrm{TiO}_{2}-\mathrm{ZrO}_{2}$ catalysts under superheated steam conditions. Fuel 167(1):288-294

Liu H, Cheng L, Huang S, Jia P, Xiong H (2018) Heat and mass transfer characteristics of superheated fluid for hybrid solvent-steam process in perforated horizontal wellbores. Int J Heat Mass Transf 122:557-573

Muradov K, Davies D (2012) Temperature transient analysis in horizontal wells: application workflow, problems and advantages. J Pet Sci Eng 92-93:11-23

Venkatramani AV, Okuno R (2018) Mechanistic simulation study of expanding-solvent steam-assisted gravity drainage under reservoir heterogeneity. J Pet Sci Eng 169:146-156

Xu A, Mu L, Fan Z, Wu X et al (2013) Mechanism of heavy oil recovery by cyclic superheated steam stimulation. J Pet Sci Eng 111:197-207

Zargar Z, Ali SMF (2018) Analytical modelling of steam chamber rise stage of steam-assisted gravity drainage (SAGD) process. Fuel 233(1):732-742

Publisher's Note Springer Nature remains neutral with regard to jurisdictional claims in published maps and institutional affiliations. 